\section{Growth and Productivity of Green-growing and Dormant 'Chardonnay' Benchgrafts during Vineyard Establishment}

\author{
Larry J. Bettiga ${ }^{1}$
}

ADDITIONAL INDEX WORDS. vine development, grape, rootstock, Vitis vinifera

SUMMARY. Vine growth and yield variables were measured for grape (Vitis vinifera) planted as green-growing and dormant 'Chardonnay' benchgrafts during the first 8 years after vineyard establishment. Benchgrafts of 'Freedom' and 'Kober 5BB' rootstock were evaluated. Vines planted as green-growing benchgrafts had smaller trunk and cordon diameters and lower pruning weights. Growth variables measured were higher for 'Freedom' benchgrafts than 'Kober 5BB'. Yields were higher for vines planted as dormant benchgrafts in three of the first six production years when compared with vines established with green-growing plants. Productivity was higher for vines planted with dormant benchgrafts or grafted on 'Freedom' rootstock because the permanent framework of vines in these treatments was fully developed earlier in the training process, which allowed for earlier crop production.

$\mathrm{D}$ uring the mid to late $1980 \mathrm{~s}$ in the Salinas Valley (Monterey County) of California, susceptible own-rooted vineyards infested with grape phylloxera (Daktulosphaira vitifoliae) were replanted to wine grape cultivars grafted on resistant rootstocks and the use of potted green-growing benchgrafts as planting stock became a more common practice compared with the traditional field grown dormant bare rooted benchgrafted vines. Green-growing plants are grafted, callused, placed in a pot, and then are greenhouse grown. They are acclimated to outdoor conditions before planting in the same year they are grafted. Dormant bare rooted benchgrafts are grafted, callused, and then are field grown in a nursery row and are dug in the late fall or winter and are held in cold storage until delivery to the planting site (Hartmann et al., 1997; Winkler et al., 1974). When using greengrowing vines a high percent plant loss and vines with poor growth during the first year can increase the time required to fully train vines, and the time required to achieve full production potential of the vineyard.

University of California Cooperative Extension, 1432 Abbott Street, Salinas, CA 93901

I thank Evan Oakes, Riesa Bigelow, and Diana Henderson for technical assistance and the management and staff of the Pinnacles Vineyard, Soledad, $\mathrm{CA}$, for cooperation and material assistance. The Monterey County Grape Grower Association provided partial funding.

${ }^{1}$ Corresponding author. E-mail: lbettiga@ucanr.edu.
Poor growth of green-growing benchgrafts can be attributed to poor root development, the lack of adequate hardening-off of the green leaf tissue before planting, high air temperatures at planting, or post-plant management practices (L.J. Bettiga, personal observation). Irrigation practice is critical and both excessive and insufficient amounts of applied water can result in poor growth (Beede and Christensen, 2000). The extensive winds in the Salinas Valley are also a major factor in the stress seen in green-growing benchgrafted plants. Winds in the Salinas Valley have been shown to reduce total vine canopy growth (Bettiga et al., 1996).

During training, the rate of development of the permanent structures (trunk and cordons) of a vine and in what year after planting crop production will begin, depends on vine vigor and capacity. Vine vigor is a measure of the rate of vine growth, whereas, vine capacity is the total annual vegetative and fruit biomass produced and reflects the vines ability for total production rather than rate of activity (Winkler et al., 1974). Thus, vine capacity is difficult to measure since it requires an annual determination of total vine growth. In commercial grape production, annual pruning weight is often used to estimate vine capacity (Reynolds, 2010). Partridge (1925) was an early proponent of using pruning weight to indicate a vines capacity in the following season. In addition to vigor and pruning weights, visual assessment of trunk and cordon diameter at dormancy is a common practice used during the pruning of young vines to determine the rate of development of the permanent framework and thus the severity of the pruning to be performed during training (Winkler et al., 1974).

Viticulture production texts have stated that the postplanting care of green-growing benchgrafts is critical to its successful use in developing vineyards (Beede and Christensen, 2000; Winkler et al., 1974). Yet, there are very little published data on the development of grafted vines as a function of different nursery practices, but such data could be very useful for growers who may now purchase several types of planting stock. The purpose of this study was to evaluate growth and yield of grapevines during the initial years after planting and determine how performance was affected by benchgraft type and vine vigor as influenced by rootstock.

\section{Materials and methods}

This study was conducted from 1990 to 1997 in a commercial vineyard southeast of the city of Soledad, CA (lat. $36^{\circ} 26^{\prime} 21^{\prime \prime} \mathrm{N}$, long. $121^{\circ} 18^{\prime} 23^{\prime \prime} \mathrm{W}$, altitude $322 \mathrm{ft}$ ). The experimental site was within a commercial vineyard of grapevines of the same age and all vines were subjected to cultural practices considered

\begin{tabular}{llll}
\hline $\begin{array}{l}\text { Units } \\
\text { To convert U.S. to SI, } \\
\text { multiply by }\end{array}$ & U.S. unit & SI unit & $\begin{array}{l}\text { To convert SI to U.S., } \\
\text { multiply by }\end{array}$ \\
\hline 0.3048 & $\mathrm{ft}$ & $\mathrm{m}$ & 3.2808 \\
3.7854 & $\mathrm{gal}$ & $\mathrm{L}$ & 0.2642 \\
2.54 & inch(es) & $\mathrm{cm}$ & 0.3937 \\
25.4 & inch(es) & $\mathrm{mm}$ & 0.0394 \\
0.4536 & $\mathrm{lb}$ & $\mathrm{kg}$ & 2.2046 \\
1.6093 & mile $(\mathrm{s})$ & $\mathrm{km}$ & 0.6214 \\
28.3495 & $\mathrm{oz}$ & $\mathrm{g}$ & 0.0353 \\
$\left({ }^{\circ} \mathrm{F}-32\right) \div 1.8$ & ${ }^{\circ} \mathrm{F}$ & ${ }^{\circ} \mathrm{C}$ & $\left({ }^{\circ} \mathrm{C} \times 1.8\right)+32$ \\
& & & \\
\hline
\end{tabular}


typical for a newly planted vineyard in the Salinas Valley (L.J. Bettiga, personal observation). The soil at the site is classified as Chualar loam (U.S. Department of Agriculture, 1978). This series is classified as a fine loamy, mixed, superactive, thermic, Typic Argixerolls. The monthly and annual accumulation of degree days above $10{ }^{\circ} \mathrm{C}$ (Table 1 ) was determined by the single sine method (Zalom et al., 1983) from the California Irrigation Management Information System Weather Station no. 114 (California Department of Water Resources) located $10 \mathrm{~km}$ from the experimental site for the 1993 to 1997 growing seasons. The vineyard was irrigated by a drip system that had two $0.5-\mathrm{gal} / \mathrm{h}$ pressure-compensating emitters per vine that were spaced $\approx 12$ inches from either side of the vine trunk. During the years that data were collected, the vines were irrigated on a weekly schedule as determined by the grower. Irrigation timing and volume of applied water was typical for a developing vineyard in the area

Table 1 . The monthly and total growing degree days (GDD) above $10{ }^{\circ} \mathrm{C}$ in 1993-97 at Soledad, CA.

\begin{tabular}{lrrrrr}
\hline & \multicolumn{5}{c}{ GDD $\left({ }^{\circ} \mathbf{C}\right)^{\mathbf{z}}$} \\
\cline { 2 - 6 } Mo. & $\mathbf{1 9 9 3}$ & $\mathbf{1 9 9 4}$ & $\mathbf{1 9 9 5}$ & $\mathbf{1 9 9 6}$ & $\mathbf{1 9 9 7}$ \\
\hline April & 184 & 153 & 146 & 199 & 174 \\
May & 254 & 178 & 174 & 211 & 270 \\
June & 277 & 232 & 219 & 227 & 235 \\
July & 276 & 238 & 304 & 302 & 271 \\
August & 310 & 260 & 276 & 276 & 318 \\
September & 254 & 248 & 257 & 234 & 319 \\
October & 234 & 200 & 226 & 196 & 204 \\
Total GDD $\left({ }^{\circ} \mathrm{C}\right)$ & 1789 & 1509 & 1602 & 1645 & 1791 \\
\hline
\end{tabular}

Table 2. Effect of rootstock and benchgraft type on pruning weight of 'Chardonnay' grapevines collected in Dec. 1990-97 at Soledad, CA.

\begin{tabular}{|c|c|c|c|c|c|c|c|}
\hline \multirow[b]{3}{*}{ Treatment } & \multicolumn{7}{|c|}{ Pruning wt $(\mathrm{kg} / \text { vine })^{\mathrm{z}}$} \\
\hline & \multicolumn{7}{|c|}{$\mathbf{Y r}^{\mathrm{y}}$} \\
\hline & 1990 & 1992 & 1993 & 1994 & 1995 & 1996 & 1997 \\
\hline \multicolumn{8}{|l|}{ Rootstock } \\
\hline 'Freedom' & 0.030 & 0.25 & 0.76 & 0.96 & 2.0 & 1.50 & 1.35 \\
\hline 'Kober 5BB' & 0.015 & 0.08 & 0.41 & 0.63 & 1.6 & 0.98 & 0.84 \\
\hline$P>\mathrm{F}$ & $<0.01$ & $<0.01$ & $<0.01$ & $<0.01$ & $<0.01$ & $<0.01$ & $<0.01$ \\
\hline \multicolumn{8}{|l|}{ Benchgraft } \\
\hline Dormant & 0.043 & 0.26 & 0.78 & 0.95 & 2.0 & 1.40 & 1.22 \\
\hline Green & 0.002 & 0.07 & 0.39 & 0.63 & 1.6 & 1.08 & 0.98 \\
\hline$P>\mathrm{F}$ & $<0.01$ & $<0.01$ & $<0.01$ & $<0.01$ & $<0.01$ & $<0.01$ & 0.02 \\
\hline Rootstock $\times$ benchgraft $(P>\mathrm{F})$ & $<0.01$ & 0.03 & 0.14 & 0.523 & 0.37 & 0.65 & 0.16 \\
\hline
\end{tabular}

${ }^{\mathrm{z}} 1 \mathrm{~kg}=2.2046 \mathrm{lb}$

yata not collected in the first year of training (1991) as summer pruning removed shoots that were not required to be retained to develop the vine permanent structures.

to avoid water becoming a limiting factor for vine growth and were based on soil moisture monitoring (using a soil probe and determining soil moisture by feel) and visual assessment of growth. The experimental was a randomized complete with 12 replications of fou ofots. The two factors evaluated were benchgraft type (dormant and green-growing) and rootstock ('Freedom' and 'Kober . 'Kober 5BB' and 'Freedom' a moderate and high vigor stock, respectively. The scion cultivar was Chardonnay (selection UCD FPS 4). Plant material was obtained from a commercial grapevine nursery and the benchgrafts were propagated previously described. The dormant age at the removed from the field in early winter. Upon delivery, they were placed in moist wood shavings for $10 \mathrm{~d}$ at ambient conditions and planted when

Hortlechnology · December 2015 25(6) the buds began to swell. The green benchgrafts were acclimated to outdoor conditions at the nursery and were planted upon delivery. The dormant vines were planted on $10 \mathrm{Apr}$. 1990 and the green-growing vines on 22 May 1990. Vines were allowed to grow untrained in 1990 and were pruned to a single two-bud spur at dormancy in Dec. 1990. In 1991, vines were trained to bilateral cordons on a vertical shoot positioned trellis, which was composed of a permanent cordon wire at 42 inches aboveground level and two pairs of moveable foliage wires at 53 and 63 inches. The vine spacing was $6 \mathrm{ft}$ within rows and $12 \mathrm{ft}$ between rows. The rate of vine training during 1991 and in successive years was dependent on vine size by visually accessing cane length and diameter during dormant pruning. When fully trained each cordon was $\approx 36$ inches long and vines were pruned to a maximum of 40 retained nodes per vine based on vine capacity by adjusting the number of two-node spurs.

Measurements. Pruning weights of each vine were measured in the first winter (Dec. 1990). No growth measurements were collected in the first year of training (1991) as summer pruning removed shoots that were not required to be retained to develop the vine permanent structures. Beginning in Dec. 1992, at dormancy, the number of shoots per vine were counted, the vines pruned, and the 1year-old cane prunings from each vine were weighed. After pruning, the diameter of permanent vine structures was measured in three locations: on the trunk at 18 inches below the cordon wire, between the two proximal spur positions, and between the two distal spur positions of each cordon using a digital caliper (model CDS6CP; Mitutoyo America, Aurora, IL). As vine trunks and cordons have asymmetrical cross sections, the maximum diameter at each measurement point was recorded. For each vine, cluster numbers were counted and fruit yield was determined by weighing the harvested clusters. Average cluster weight was calculated by dividing fruit yield by the number of clusters per vine. Ravaz index was calculated by dividing the fruit yield per vine by the dormant pruning weights (Ravaz, 1911). Fruit composition was determined from a 100 -berry sample that 
was randomly selected from each twovine replicate before harvest. The berry samples were weighed to calculate average berry weight. Berries were macerated in a blender and the filtered juice was analyzed for soluble solids using a handheld temperature compensating refractometer (model 10423; Reichert Scientific Instruments, Buffalo, NY). Juice $\mathrm{pH}$ was measured by $\mathrm{pH}$ meter (model 920A; ATI Orion, Boston, MA) and titratable acidity by titration with $0.133 \mathrm{~N}$ sodium hydroxide to a $\mathrm{pH}$ endpoint of 8.20. The data were subjected to a two-factor analysis of variance for each year (SuperANOVA; Abacus Concepts, Berkeley, CA).

\section{Results and discussion}

Growth variables. Pruning weights were affected by both rootstock and benchgraft type. The more vigorous rootstock, 'Freedom', had greater pruning weights than 'Kober 5 BB' (Table 2) in all years of the study. In 1990 and 1992, there was a significant rootstock $\times$ benchgraft interaction; although the 'Freedom' green-growing benchgrafts had higher pruning weights than the 'Kober 5BB' green-growing benchgrafts, the differences were not significant in 1990 and 1992 as compared with 1993-97 (data not shown). Vines planted as dormant benchgrafts also had greater pruning weights than green-growing plants (Table 2 ) for all years. Figure 1 shows a typical example of the growth differences observed between the benchgraft types during the first growing season. Observations made on individual vine development during the first 3 years of vine training (Table 3 ) show that both using a more vigorous rootstock and dormant benchgrafts resulted in a greater development of the trunk and cordons. Scion vine vigor has been shown to be influenced by rootstock (Ollat et al., 2003; Pouget, 1987; Rives, 1971). The faster cordon and spur position development allowed for more shoots per vine for 'Freedom' in 1993 and for dormant benchgrafts in 1993, 1994, and 1995 (Table 4). Trunk and cordon diameters at the proximal (Table 5) and distal (data not shown) ends all were greater on vines planted with 'Freedom' rootstock or dormant benchgrafts for all years. Using pruning weight and diameter data as an estimate of vine size demonstrates the advantage of using dormant benchgrafts and a more vigorous rootstock to reduce the time to achieve fully developed vine permanent structures under the site conditions of this study. Yields were higher for vines planted
Yield AND FRUit VARIABles.

as dormant benchgrafts in three (1992, 1993, and 1995) of the first six production years when compared with vines established with greengrowing plants (Table 6). Vines on 'Freedom' also had higher yields in 1992, 1994, and 1997. In years when there was a difference in yield, the increase was because of higher

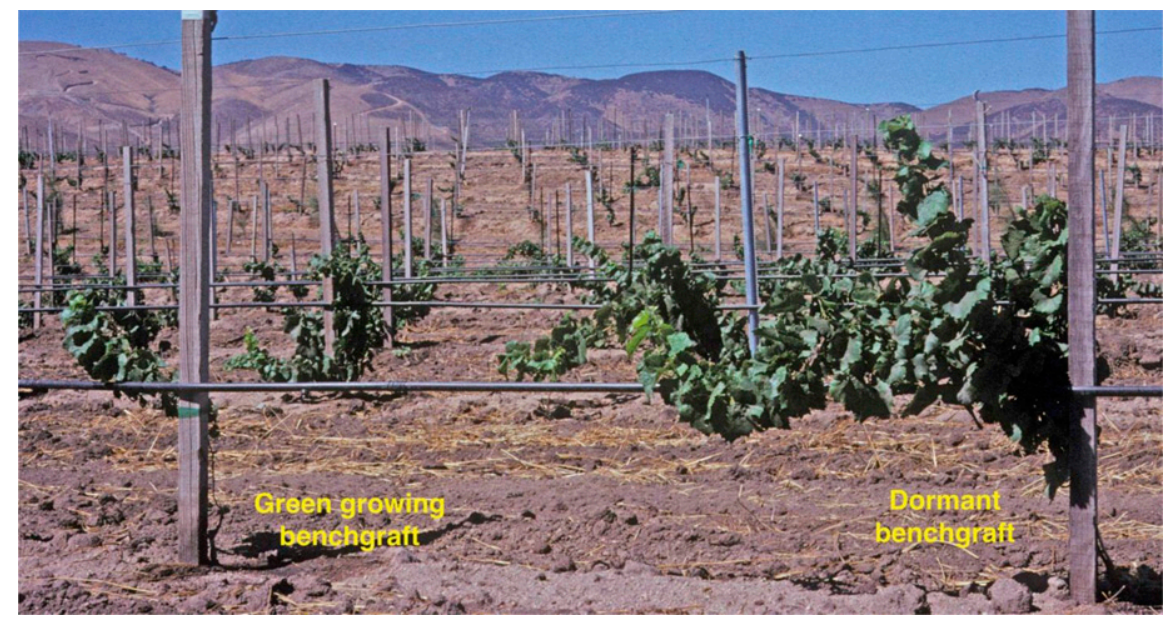

Fig. 1. Comparison of first year (1990) late season growth on green-growing (left) and dormant (right) 'Chardonnay' grapevine benchgrafts on 'Freedom' rootstock.

Table 3. Effect of rootstock and benchgraft type on the progression of trunk and cordon development during the first 3 years of vine training of 'Chardonnay' grapevines in 1991-93 at Soledad, CA.

\begin{tabular}{|c|c|c|c|c|c|c|c|c|c|}
\hline \multirow[b]{3}{*}{ Factor } & \multicolumn{9}{|c|}{ Vines in each category at dormancy (\%) } \\
\hline & \multicolumn{3}{|c|}{ Trunk only } & \multicolumn{3}{|c|}{ Partial cordons } & \multicolumn{3}{|c|}{ Full cordons } \\
\hline & $1991^{\mathrm{z}}$ & 1992 & 1993 & 1991 & 1992 & 1993 & 1991 & 1992 & 1993 \\
\hline \multicolumn{10}{|l|}{ 'Freedom' } \\
\hline Dormant & 42 & 4 & 0 & 25 & 4 & 4 & 29 & 92 & 96 \\
\hline Green & 42 & 9 & 0 & 4 & 23 & 4 & 4 & 68 & 96 \\
\hline \multicolumn{10}{|l|}{ 'Kober 5BB' } \\
\hline Dormant & 71 & 0 & 0 & 29 & 12 & 4 & 0 & 88 & 96 \\
\hline Green & 25 & 29 & 0 & 0 & 38 & 4 & 0 & 33 & 96 \\
\hline
\end{tabular}

${ }^{z}$ The percentage of vines cut back to a two-bud spur at dormancy of the first training year (1991) was $4 \%, 50 \%, 0 \%$, and $75 \%$ for 'Freedom' dormant, 'Freedom' green, 'Kober 5BB' dormant, and 'Kober 5BB' green, respectively.

Table 4. Effect of rootstock and benchgraft type on shoot number of 'Chardonnay' grapevines in 1993-97 at Soledad, CA.

\begin{tabular}{lccccc}
\hline & \multicolumn{5}{c}{ Shoots (no./vine) } \\
\cline { 2 - 6 } & \multicolumn{5}{c}{ Yr } \\
\cline { 2 - 6 } Factor & $\mathbf{1 9 9 3}$ & $\mathbf{1 9 9 4}$ & $\mathbf{1 9 9 5}$ & $\mathbf{1 9 9 6}$ & $\mathbf{1 9 9 7}$ \\
\hline Rootstock & 22 & 37 & 38 & 39 & 54 \\
$\quad$ 'Freedom' & 18 & 35 & 37 & 38 & 50 \\
$\quad$ Kober 5BB' & 0.01 & 0.18 & 0.44 & 0.41 & $<0.01$ \\
$P>$ F & & & & & \\
Benchgraft & 25 & 39 & 40 & 39 & 53 \\
$\quad$ Dormant & 16 & 33 & 35 & 38 & 51 \\
$\quad$ Green & $<0.01$ & $<0.01$ & $<0.01$ & 0.26 & 0.05 \\
$P>$ F & 0.30 & 0.20 & 0.68 & 0.68 & 0.30 \\
Rootstock $\times$ benchgraft $(P>\mathrm{F})$ & & & & & \\
& & & & &
\end{tabular}


number of clusters per vine (Table 7). Especially in the early production years, the faster development of the cordons resulted in more shoots and clusters per vine for both vines planted with dormant benchgrafts or grafted on 'Freedom'. In 1996, there was a significant rootstock $x$ benchgraft interaction; this was the only year where 'Kober 5BB' dormant benchgraft vines had higher yield than the other treatment combinations. From the first production year there was a trend of increasing yields in successive years (Table 6) with the exception of 1995 when low temperatures during bloom in May 1994 reduced bud fruitfulness and May 1995 (Table 1) reduced fruit set, which is reflected in the lower cluster numbers and weights for that year (Table 7). Cluster weights for vines grafted on 'Kober 5BB' were higher than those on 'Freedom' in the first two production years (1992 and
1993). There were no differences in cluster weights between the dormant and green-growing benchgrafts.

For most of the years of the study the Ravaz index (Table 6) was within the value of 5-10 optimal range as suggested for an ideal wine grape canopy that is balanced to the crop load and capable of fully ripening the crop (Kliewer and Dokoozlian, 2005; Smart and Robinson, 1991). Vines grafted to 'Kober 5BB' had higher

Table 5. Effect of rootstock and benchgraft type on trunk and cordon diameter of 'Chardonnay' grapevines in 1992-97 at Soledad, CA $(\mathrm{n}=24)$.

\begin{tabular}{|c|c|c|c|c|c|c|c|c|c|c|c|c|}
\hline \multirow[b]{2}{*}{ Factor } & \multicolumn{12}{|c|}{$\operatorname{Diam}[\operatorname{mean} \pm \mathrm{SD}(\mathrm{mm})]^{\mathrm{z}}$} \\
\hline & \multicolumn{2}{|c|}{1992} & \multicolumn{2}{|c|}{1993} & \multicolumn{2}{|c|}{1994} & \multicolumn{2}{|c|}{1995} & \multicolumn{2}{|c|}{1996} & \multicolumn{2}{|r|}{1997} \\
\hline Rootstock & Trunk & Cordon & Trunk & Cordon & Trunk & Cordon & Trunk & Cordon & Trunk & Cordon & Trunk & Cordon \\
\hline 'Kober 5BB' & $13 \pm 3$ & $9 \pm 2$ & $18 \pm 2$ & $15 \pm 3$ & $22 \pm 2$ & $19 \pm 2$ & $27 \pm 2$ & $22 \pm 2$ & $28 \pm 2$ & $25 \pm 3$ & $30 \pm 3$ & $328 \pm 2$ \\
\hline$P>\mathrm{F}$ & $<0.01$ & $<0.01$ & $<0.01$ & $<0.01$ & $<0.01$ & $<0.01$ & $<0.01$ & $<0.01$ & $<0.01$ & $<0.01$ & $<0.01$ & $<0.01$ \\
\hline \multicolumn{13}{|l|}{ Benchgraft } \\
\hline$P>\mathrm{F}$ & $<0.01$ & $<0.01$ & $<0.01$ & $<0.01$ & $<0.01$ & $<0.01$ & $<0.01$ & $<0.01$ & $<0.01$ & $<0.01$ & 0.02 & $<0.01$ \\
\hline Rootstock $\times$ benchgraft $(P>\mathrm{F})$ & 0.74 & 0.76 & 0.24 & 0.43 & 0.17 & 0.70 & 0.58 & 0.88 & 0.79 & 0.66 & 0.74 & 0.68 \\
\hline
\end{tabular}

${ }^{2}$ Trunk diameter taken 18 inches $(45.7 \mathrm{~cm})$ below the cordon wire. Average cordon diameter between the two proximal spur positions of each cordon; $1 \mathrm{~mm}=0.0394$ inch.

Table 6. Effect of rootstock and benchgraft type on yield and Ravaz index (RI) of 'Chardonnay' grapevines in 1992-97 at Soledad, CA.

\begin{tabular}{|c|c|c|c|c|c|c|c|c|c|c|c|c|}
\hline \multirow{3}{*}{$\frac{\text { Factor }}{\text { Rootstock }}$} & \multicolumn{12}{|c|}{ Yield $(\mathrm{kg} /$ vine $)$ and $\mathrm{RI}(\text { ratio })^{\mathrm{z}}$} \\
\hline & \multicolumn{2}{|c|}{1992} & \multicolumn{2}{|c|}{1993} & \multicolumn{2}{|c|}{1994} & \multicolumn{2}{|c|}{1995} & \multicolumn{2}{|c|}{1996} & \multicolumn{2}{|c|}{1997} \\
\hline & $\mathrm{kg} /$ vine & RI & $\mathrm{kg} /$ vine & RI & $\mathrm{kg} /$ vine & RI & $\mathrm{kg} /$ vine & RI & $\mathrm{kg} /$ vine & RI & $\mathrm{kg} /$ vine & RI \\
\hline 'Kober 5BB' & 0.6 & 8.6 & 4.8 & 12.4 & 5.8 & 10.2 & 4.3 & 2.7 & 7.5 & 8.2 & 13.5 & 17.8 \\
\hline$P>\mathrm{F}$ & 0.02 & $<0.01$ & 0.06 & 0.08 & 0.02 & 0.08 & 0.15 & 0.16 & 0.10 & $<0.01$ & $<0.01$ & $<0.01$ \\
\hline \multicolumn{13}{|l|}{ Benchgraft } \\
\hline$P>\mathrm{F}$ & $<0.01$ & $<0.01$ & $<0.01$ & 0.04 & 0.98 & $<0.01$ & $<0.01$ & 0.51 & 0.23 & 0.01 & 0.33 & 0.02 \\
\hline Rootstock $\times$ benchgraft $(P>\mathrm{F})$ & 0.16 & 0.08 & 0.10 & 0.04 & 0.28 & 0.59 & 0.51 & 0.34 & 0.02 & 0.88 & 0.20 & 0.87 \\
\hline
\end{tabular}

${ }^{\mathrm{z}} \mathrm{l} \mathrm{kg}=2.2046 \mathrm{lb}, \mathrm{RI}=$ ratio of yield $(\mathrm{kg} /$ vine $)$ to pruning weight $(\mathrm{kg} /$ vine $)$.

Table 7. Effect of rootstock and benchgraft type on cluster number and weight of 'Chardonnay' grapevines in 1992-97 at Soledad, CA.

\begin{tabular}{|c|c|c|c|c|c|c|c|c|c|c|c|c|}
\hline \multirow{3}{*}{$\frac{\text { Factor }}{\text { Rootstock }}$} & \multicolumn{12}{|c|}{ Cluster (no./vine) and wt $(\mathrm{g})^{\mathrm{z}}$} \\
\hline & \multicolumn{2}{|c|}{1992} & \multicolumn{2}{|c|}{1993} & \multicolumn{2}{|c|}{1994} & \multicolumn{2}{|c|}{1995} & \multicolumn{2}{|c|}{1996} & \multicolumn{2}{|c|}{1997} \\
\hline & no./vine & wt $(g)$ & no./vine & wt (g) & no./vine & wt (g) & no./vine & wt $(\mathrm{g})$ & no./vine & wt $(g)$ & no./vine & wt $(\mathrm{g})$ \\
\hline 'Kober 5BB' & 3 & 223 & 29 & 165 & 42 & 139 & 42 & 103 & 48 & 157 & 79 & 171 \\
\hline$P>\mathrm{F}$ & 0.01 & $<0.01$ & $<0.01$ & $<0.01$ & 0.04 & 0.17 & 0.19 & 0.56 & 0.63 & 0.06 & 0.08 & 0.17 \\
\hline Benchgraft & & & & & & & & & & & & \\
\hline$P>F$ & $<0.01$ & 0.50 & $<0.01$ & 0.12 & 0.53 & 0.65 & $<0.01$ & 0.75 & 0.02 & 0.30 & 0.18 & 0.67 \\
\hline $\begin{array}{l}\text { Rootstock } \times \\
\quad \text { benchgraft }(P>\mathrm{F})\end{array}$ & 0.12 & 0.06 & 0.11 & 0.67 & 0.56 & 0.30 & 0.55 & 0.72 & 0.05 & 0.28 & 0.14 & 0.02 \\
\hline
\end{tabular}


Table 8. Effect of rootstock and benchgraft type on juice soluble solids of 'Chardonnay' grapevines in 1992-97 at Soledad, CA.

\begin{tabular}{lcccccc}
\hline & \multicolumn{6}{c}{ Soluble solids (\%) } \\
\cline { 2 - 7 } & \multicolumn{7}{c}{ Yr } \\
\cline { 2 - 7 } Factor & $\mathbf{1 9 9 2}$ & $\mathbf{1 9 9 3}$ & $\mathbf{1 9 9 4}$ & $\mathbf{1 9 9 5}$ & $\mathbf{1 9 9 6}$ & $\mathbf{1 9 9 7}$ \\
\hline Rootstock & & & & & & \\
$\quad$ 'Freedom' & 21.8 & 23.6 & 22.1 & 22.8 & 24.3 & 23.1 \\
$\quad$ 'Kober 5BB' & 22.0 & 23.4 & 22.7 & 23.2 & 24.9 & 23.0 \\
$P>$ F & 0.14 & 0.39 & $<0.01$ & $<0.01$ & $<0.01$ & 0.48 \\
Benchgraft & & & & & & \\
$\quad$ Dormant & 21.8 & 23.5 & 22.2 & 22.9 & 24.4 & 23.1 \\
$\quad$ Green & 22.0 & 23.4 & 22.6 & 23.1 & 24.7 & 23.0 \\
$P>$ F & 0.08 & 0.71 & $<0.01$ & 0.03 & 0.01 & 0.46 \\
Rootstock $\times$ benchgraft $(P>$ F $)$ & 0.56 & 0.86 & 0.47 & 0.03 & 0.04 & 0.61 \\
\hline
\end{tabular}

Ravaz index values for 3 of the first 6 years the plants were cropped. Vines planted as green benchgrafts had lower Ravaz values in the first cropping year (1992) because of low cluster numbers from the reduced number of retained nodes on spurs; however, higher values occurred in four of the remaining years. Grape maturity as measured by percent soluble solids was higher for vines grafted on 'Kober 5BB' or planted as green benchgrafts in 1994, 1995, and 1996 (Table 8). The higher soluble solids of vines on 'Kober 5BB' was not related to crop load. Vines planted as green-growing benchgrafts had consistently lower yield and in general higher Ravaz index values. In the years when higher soluble solids occurred there was a corresponding increase in juice $\mathrm{pH}$ and a lower titratable acidity (data not shown).

\section{Conclusion}

The results from this study show that vine development can be hastened by planting dormant benchgrafts as compared with a greengrowing benchgrafts under the cool windy conditions of the Salinas Valley. Dormant plant material developed larger plants as measured by pruning weight and trunk and cordon diameters. The March and April planting period that is possible with dormant plant material allows for earlier canopy development that is conditioned to the site environment and avoids the stresses of wind and temperature that can adversely affect green-growing vines planted in May of the green-growing plants in the first year resulted in a delay in the development of the trunk, cordons, and spur positions. These vines therefore produced a smaller yield during the first 8 years after planting. For sites where low vigor delays vine development, the use of a rootstock that induces greater plant vigor was shown to reduce the time to develop the vine and achieve full production capacity. The delay in vine development using green-growing benchgrafts was consistent for both the moderate and higher vigor rootstocks tested. Because green-growing benchgrafts continue to be used as planting stock, growers who are establishing vineyards need to be aware of environmental conditions that can result in early growth and yield advantages using dormant plant material.

\section{Literature cited}

Beede, R.H. and L.P. Christensen. 2000. Planting a raisin vineyard, p. 64-70. In: L.P. Christensen (ed.). Raisin production manual. Univ. California, Agr. Natural Resources, Oakland, CA

Bettiga, L.J., N.K. Dokoozlian, and L.E. Williams. 1996. Windbreaks improve the growth and yield of Chardonnay grapevines in a cool climate, Sec. II, p. 43-46. In: T. Henick-Kling, T.E. Wolf, and E.M. Harkness (eds.). Proc. Fourth Intl. Cool Climate Viticult. Enol. Symp., New York State Agr. Expt. Sta., Geneva, NY.

Hartmann, H.T., D.E. Kester, F.T. Davies, and R.L. Geneve. 1997. Plant propagation: and June. The reduced total growth
Principles and practice. 6th ed. Prentice Hall, Upper Saddle River, NJ.

Kliewer, W.M. and N.K. Dokoozlian. 2005. Leaf area/crop weight ratios of grapevines: Influence on fruit composition and wine quality. Amer. J. Enol. Viticult. 56:170-181.

Partridge, N.L. 1925. The use of the growth-yield relationship in field trials with grapes. Proc. Amer. Soc. Hort. Sci. 23:131-134.

Pouget, R. 1987. Usefulness of rootstocks for controlling vine vigour and improving wine quality. Acta Hort. 206:109-118.

Ollat, N., J.P. Tandonnet, M. Lafontaine, and H.R. Schultz. 2003. Short and long term effects of three rootstocks on Cabernet Sauvignon vine behaviour and wine quality. Acta Hort. 617:95-100.

Ravaz, M.L. 1911. L'effeuillage de la vigne. Annales de l'Ecole Nationale d'Agriculture de Montpellier 11:216244.

Reynolds, A.G. 2010. Viticultural and vineyard management practices and their effects on grape and wine quality, p. 365444. In: A.G. Reynolds (ed.). Managing wine quality. Volume 1: Viticulture and wine quality. Woodhead Publishing, Oxford, UK.

Rives, M. 1971. Statistical analysis of rootstock experiments as providing a definition of the terms of vigour and affinity in grapes. Vitis 9:280-290.

Smart, R.E. and M.D. Robinson. 1991. Sunlight into wine: A handbook for winegrape canopy management. Winetitles, Adelaide, Australia.

U.S. Department of Agriculture. 1978. Soil survey of Monterey County, California. 12 Aug. 2015. <http://www. nrcs.usda.gov/Internet/FSE MANUSCRIPTS/california/CA053/0/ monterey.pdf>.

Winkler, A.J., J.A. Cook, W.M. Kliewer, and L.A. Lider. 1974. General viticulture. 2nd ed. Univ. California Press, Berkeley, CA.

Zalom, F.G., P.B. Goodell, L.T. Wilson, W.W. Barnett, and W.J. Bentley. 1983. Degree-days: The calculation and use of heat units in pest management. Univ. California Agr. Natural Resources Lflt. 21373. 